\title{
Influence of preparation methods on the performance of cold-mixed epoxy bitumen
}

\author{
Quan Liu (1) C Chonghui Wang · Zeyu Zhang · Cong Du • Pengfei Liu • \\ Markus Oeser
}

Received: 20 November 2020/ Accepted: 20 February 2021/Published online: 23 March 2021

(C) The Author(s) 2021

\begin{abstract}
Cold-mixed epoxy bitumen (CEB) has been presented as an eco-friendly paving material used for steel bridge deck pavements. This study performed an investigation on three preparation methods of CEBs, which includes one kind of three-component and two kinds of two-component methods. The curing process was characterized through the viscosity measurement. Meanwhile, the microstructure of CEBs was observed using fluorescence microscopy. Mechanical properties of CEBs prepared with different methods were characterized by employing direct tensile tests and dynamic mechanical analysis (DMA). Finally, thermogravimetric analysis (TGA/DTG) was conducted to feature the thermal stability of CEBs. The results indicated that the preparation methods
\end{abstract}

Q. Liu $(\bowtie) \cdot$ C. Wang $\cdot$ Z. Zhang .

C. $\mathrm{Du} \cdot \mathrm{P} . \mathrm{Liu} \cdot \mathrm{M}$. Oeser

Institute of Highway Engineering, RWTH Aachen

University, 52074 Aachen, Germany

e-mail: q.liu@isac.rwth-aachen.de

C. Wang

e-mail: c.wang@isac.rwth-aachen.de

Z. Zhang

e-mail: zeyu.zhang@isac.rwth-aachen.de

C. Du

e-mail: du@isac.rwth-aachen.de

P. Liu

e-mail: liu@isac.rwth-aachen.de

M. Oeser

e-mail: oeser@isac.rwth-aachen.de significantly affected the performance of cured CEBs, although the same mix design was adopted. The curing temperature determined the curing rate of CEBs, while the preparation methods dominated the morphological characteristic of cured CEBs. The three-component preparation method can achieve acceptable mechanical performance for engineering requirements. As for two-component methods, the curing agent is supposed to be mixed with bitumen to obtain satisfying microstructures of CEBs.

Keywords Cold-mixed epoxy bitumen $\cdot$ Preparation method $\cdot$ Mechanical properties $\cdot$ Microscopic morphology $\cdot$ Thermal stability

\section{Introduction}

Bituminous materials have been extensively used in the pavement construction for over a century $[1,2]$. Although much effort is being spent improving the road performance of asphaltic pavement, traffic volume increase precipitates a need for continual improvements to pavement materials [3-5]. For this reason, bitumen modification has been popularized for decades to expand the service life of pavement $[6,7]$. To date, there have been numerous products developed for bitumen modification, including styrenebutadiene-styrene block copolymer (SBS) [8], butadiene-styrene copolymer (SBR) [9], ethylene-vinyl 
acetate (EVA) [10, 11], Polyethylene (PE) [12], and epoxy [13, 14]. Among these, epoxy bitumen (EB) has been most widely accepted in constructing steel bridge deck pavements $[15,16]$.

Epoxy bitumen refers to a blend of epoxy resin, curing agent, bitumen, and other additives [17]. The thermosetting epoxy resin chemically reacts with the curing agent, forming a 3-D network during the blending [18]. Consequently, the thermoplastic bitumen and thermosetting epoxy resin comprise a polymer composite with thermoplastic and thermosetting behavior [19]. The epoxy bitumen presents sound mechanical properties due to the two-phase structure. $\mathrm{Yu}$ et al. [20] reported that, when the epoxy resin content was beyond $30 \%$, the epoxy bitumen microstructure transformed from bitumen-dominant to epoxy-dominant composite, inducing remarkable strength improvement. In addition to the prescription of epoxy bitumen, the mechanical properties of cured EBs are affected by curing behaviors. A well crosslinked epoxy bitumen performs superior to one with low cross-linking densities. It has been demonstrated that the curing process is associated with the curing temperature and method [21, 22]. According to the curing temperature, epoxy bitumen can be subdivided into high-temperature mixed epoxy bitumen (HEB), warm-mixed epoxy bitumen (WEB), and cold-mixed epoxy bitumen (CEB), respectively.

By far, the HEB and WEB have been studied and well understood [23]. HEB is usually made from epoxy resin, bitumen, curing agent, and some additives. In the study of Cong et al. [24], the HEB samples were prepared by heating modified bitumen above $160{ }^{\circ} \mathrm{C}$. Subsequently, the epoxy resin was added into the flowable bitumen, and meanwhile, the high shear mixer was utilized to disperse the epoxy resin in the bitumen. Finally, a curing agent was incorporated to form the HEB sample. Unlike the preparation method conducted by Cong et al. [24], Yin et al. [23] prepared the HEB sample using the two-component method. In specific, the epoxy resin was firstly mixed with the curing agent. In what follows, the bitumen was also heated to $160{ }^{\circ} \mathrm{C}$, and then added to the mixture of epoxy resin and curing agent. The preparation method of WEB usually conforms to that of HEB. The only difference locates at the use of warm-mixed additives to low the viscosity of bitumen so that the mixing temperature can be reduced to $120^{\circ} \mathrm{C}$ [25]. Luo et al. [26] compared the performance of WEB and HEB. In his research, the HEB was prepared using the threecomponent method while the two-component method prepared the WEB. The results showed that WEB was preferable to use in the new bridge pavement while the HEB behaved better in bridge pavement maintenance and rehabilitation.

Previous studies regarding the HEB and WEB demonstrated that both two-component and threecomponent were acceptable in practice depending on the construction requirement. In terms of the CEB, the temperature reduction of epoxy bitumen mixing was achieved by introducing a diluent into bitumen. The cold-mixed epoxy bitumen is a promising material due to its merit in reducing energy consumptions and gas emission [27]. In particular, the waterborne epoxy bitumen emulsion (WEBB), which belongs to a special kind of cold-mixed epoxy bitumen, comprises the waterborne epoxy resin and bitumen emulsion. At ambient temperature, both waterborne epoxy resin and bitumen emulsion are with very low viscosity. In this case, the preparation of WEBB does not require additional heating effort. Li et al. [28] demonstrated that the incorporation of waterborne epoxy resin could significantly increase the rutting resistance of bitumen emulsion. By far, many efforts have been made to improve the mechanical properties and compatibility of the epoxy bitumen. Zhang et al. [29] introduced a flexible chain into cured epoxy resin to improve the fatigue-resistance ability of cold-mixed epoxy bitumen. The results indicated the modified cold-mixed epoxy bitumen satisfied the requirement of engineering. Chen et al. [30] studied the mechanical and thermo-mechanical properties of the cold-mixed epoxy bitumen. They claimed that the addition of a halogen-free flame retardant could efficiently improve the tensile strength and thermal stability of cold-mixed epoxy bitumen. It was also reported that the compatibility between resin and bitumen should be a critical factor that cannot be ignored. Si et al. [31] adopted the epoxy soybean oil (ESO) to modify the compatibility of cold-mixed epoxy bitumen. They demonstrated that the addition of ESO could not only improve the compatibility of cold-mixed epoxy bitumen but also increase the elongation at break and modulus of coldmixed epoxy bitumen.

The most representative CEB products originate from either the USA or Japan [32]. Epoxy bitumen from the USA consists of two components, namely A and $\mathrm{B}$. Component $\mathrm{A}$ is the Bisphenol-A epoxy resin, 
and component $\mathrm{B}$ represents a mix of base bitumen, curing agent, and other additives. In Japan, a threecomponent preparation process is popular that includes epoxy resin (A), curing agent (B), and base bitumen with additives (C). To some extent, the threecomponent epoxy bitumen is more convenient for construction as it requires a shorter curing time compared with the one from the USA [29]. However, the effect of preparation methods on the CEB is still unknown.

Therefore, this study aims to investigate the effect of preparation methods of CEB on the performance of cold-mixed epoxy bitumen. Three preparation methods were considered, including the three-component method and two-component methods. In the following study, cured samples with different preparation methods were subjected to viscosity measurement, morphology analysis, mechanical characterization, and thermal stability analysis.

\section{Materials and sample preparation}

\subsection{Raw materials}

The $60 / 80$ pen grade bitumen was used to prepare cold-mixed bitumen. The properties of base bitumen are listed in Table 1 . The epoxy resin, namely diglycidyl ether of bisphenol-A type (DGEBA, made in Wuxi Resin, China), was adopted. The bitumen diluent was self-synthesized in the laboratory with a boiling point of $120{ }^{\circ} \mathrm{C}$ and a density of $1.156 \mathrm{~g} / \mathrm{cm}^{3}$. In specific, the bitumen was firstly heated to $135^{\circ} \mathrm{C}$. Following which, the diluent was progressively added into the bitumen with a $30 \%$ mass ratio of bitumen in total. Low weight polyamide was used as the curing agent. Additionally, other additives consisted of sodium dodecyl benzenesulfonate, dibutyl phthalate, and silane coupling agent KH550.

\subsection{Preparation of cold-mixed epoxy bitumen}

Three preparation methods marked as PM1, PM2, and PM3 were employed to prepare CEBs, as illustrated in Table 2. PM1 refers to the one with three components. Component A was the DGEBA, and component B was the curing agent. In terms of component $\mathrm{C}$, it was produced by mixing bitumen and other additives. The detailed process for the production of component $\mathrm{C}$ is illustrated as follows. Bitumen was firstly heated to $100{ }^{\circ} \mathrm{C}$ for $30 \mathrm{~min}$ to obtain sufficient mixability. Subsequently, the diluent was incorporated into fluidized bitumen and maintained mixing until no apparent cluster was observed. Following this, other additives were added with an additional mixing for 90 min. As shown in Table 2, in PM2, component A and component $\mathrm{C}$ were premixed. As for the PM3, it was obtained by premixing component $\mathrm{B}$ and component $\mathrm{C}$ in PM1. By measuring epoxy equivalent and amine equivalent, the ratio of epoxy resin to curing agent can be determined at 100:60.

Meanwhile, the proportion of bitumen to epoxy polymer (epoxy resin and curing agent) was determined by preliminary experiments, aiming to reach the optimal performance. For all cases in this study, the prescription was fixed so that the performance of cold-mixed epoxy bitumen was only affected by the preparation methods. The mixing procedure was illustrated in Fig. 1. Components A and B (C) of the CEB were mixed at the ambient temperature. The CEB samples were obtained by stirring the mixture for 3 min.

\subsection{Curing process}

As previously noted, the curing process plays a significant role in the mechanical properties of CEBs. However, this study centered on the effect of preparation methods on the performance of CEBs. For this reason, all newly blended CEB samples were
Table 1 Conventional properties of base bitumen

\begin{tabular}{lll}
\hline Properties & Measured values & Methods \\
\hline Penetration $\left(25^{\circ} \mathrm{C}\right) / 0.1 \mathrm{~mm}$ & 65 & ASTM D5 [33] \\
Ductility $\left(10^{\circ} \mathrm{C}\right) / \mathrm{cm}$ & 65 & ASTM D113 [34] \\
Viscosity $\left(60^{\circ} \mathrm{C}\right) / \mathrm{Pa} \cdot \mathrm{s}$ & 183 & ASTM D4402 [35] \\
Softening point $/{ }^{\circ} \mathrm{C}$ & 45.6 & ASTM D36 [36] \\
Density $\left(15^{\circ} \mathrm{C}\right) / \mathrm{g} / \mathrm{cm}^{3}$ & 1.033 & ASTM D70 [37] \\
\hline
\end{tabular}


Table 2 Compositions of CEBs with different preparation processes

\begin{tabular}{llll}
\hline Components & PM1 & PM2 & PM3 \\
\hline A & DGEBA & DGEBA, Bitumen, Diluent, Additives & DGEBA \\
B & Curing agent & Curing agent & Bitumen, Diluent, Curing agent, Additives \\
C & Bitumen, Diluent, Additives & - & - \\
\hline
\end{tabular}

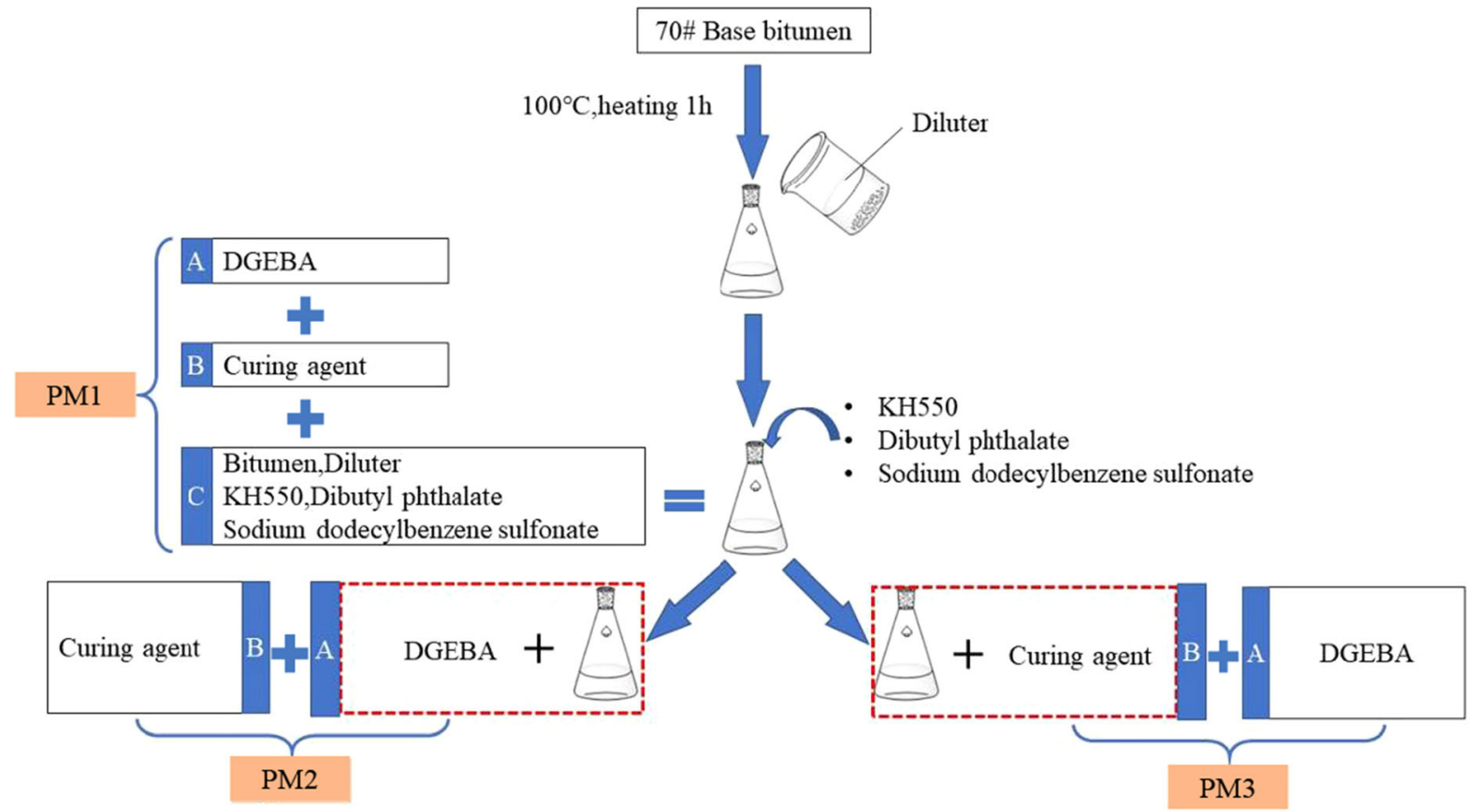

Fig. 1 Laboratory preparation of CEBs using three different methods

subjected to the same curing condition. The curing process is described as follows: CEB samples were firstly cured at ambient temperature for $24 \mathrm{~h}$. Subsequently, all the samples were maintained in the oven at $60{ }^{\circ} \mathrm{C}$ for $48 \mathrm{~h}$.

\section{Research programs}

\subsection{Research scope}

Figure 2 shows the research scope of this study. In particular, the viscosity measurement (RV) was used to characterize the curing process at the ambient temperature of newly blended CEB samples. The sampling process was performed at a 5-min interval. The cured CEBs produced by all three preparation methods were subjected to a fluorescence microscope (FM) to observe the morphology pattern from the micro-perspective. In addition, the direct tensile test (DTT) was carried out to compare the mechanical properties of CEBs with different preparation methods. Meanwhile, the dynamic mechanical analysis (DMA) was conducted to observe the phase transition as the temperature was elevated. The thermal stability of CEBs was featured using thermogravimetric analysis (TGA/DTG) in this study. Details of each test method are explained in the following section. 
Fig. 2 The flow chart of this study

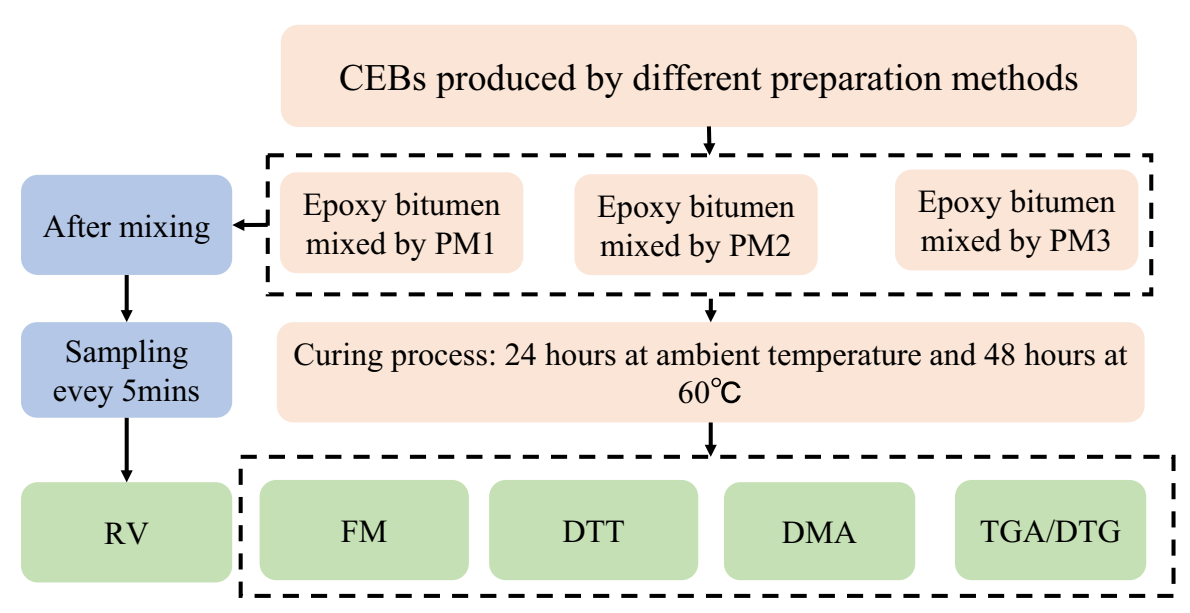

\subsection{Test methods}

\subsubsection{Rotational viscometer $(R V)$}

A Brookfield viscometer was used to measure the viscosity evolution as a function of curing time by ASTM D4402 [38]. The blend was immediately poured into the chamber with an appropriate amount at the testing temperature $\left(25^{\circ} \mathrm{C}\right.$ or $\left.60{ }^{\circ} \mathrm{C}\right)$. The spindle with the number 27 was used. The viscosity of CEBs is associated with the workability of construction. The optimal viscosity was supposed to be 2000-3000 mPa s for satisfying workability. The time duration when the viscosity of CEBs ranges from 2000 to $3000 \mathrm{mPa} \mathrm{s}$ is called workability interval. In practice, the interval time should be sufficient for pavement construction.

\subsection{Fluorescence microscope (FM)}

The fluorescence microscope allows for observation of the morphology of continuous and discontinuous phases at the microscopic level [23, 39]. Therefore, fluorescence microscopy was used to investigate the morphology of cured CEBs by identifying the bitumen phase and epoxy resin phase, respectively. Samples were examined at room temperature using an Olympic IX83 microscope with fluorescent light. The epoxy resin phase appeared green, while the bitumen phase was presented in black.

\subsection{Direct tension test (DTT)}

The direct tensile test was performed on a universal testing machine at $25^{\circ} \mathrm{C}$. Cured samples in the dumbbell shape were manufactured according to ASTM D638-96 [40]. The strain rate applied was $500 \mathrm{~mm} / \mathrm{min}$. As a result, the elongation at the breaking and tensile strength of cured samples produced by different preparation methods were recorded. Each reported value was the average of six measurements.

\subsection{Dynamic mechanical analysis (DMA)}

The storage and loss moduli and the phase angle were determined using DMA in the single-cantilever bending mode at the frequency of $1 \mathrm{~Hz}$ with a heating rate of $3{ }^{\circ} \mathrm{C} / \mathrm{min}$ from -30 to $120{ }^{\circ} \mathrm{C}$. The dimension of the specimen was $25 \mathrm{~mm} \times 5 \mathrm{~mm} \times 1.5 \mathrm{~mm}$ [23].

\subsection{Thermogravimetric analysis (TGA/DTG)}

TGA/DTG analysis of cured CEBs was performed at the heating rate of $10{ }^{\circ} \mathrm{C} / \mathrm{min}$ from 0 to $700{ }^{\circ} \mathrm{C}$ in the nitrogen atmosphere using TGA-Q 50,000 [39]. The thermogravimetric curve characterized the change of sample weight over temperature or time during the programmed temperature. The ordinate was the weight percentage, representing the weight ratio at the current temperature/time to the initial weight. The thermogravimetric differential curve indicated that the rate of weight change with temperature or time, and its peak point represents the fastest rate of weight change. 


\section{Results and discussion}

\subsection{Viscosity analysis of cured CEBs}

Figure 3 describes the viscosity evolution with curing time at $25^{\circ} \mathrm{C}$ and $60{ }^{\circ} \mathrm{C}$. Before the curing process (curing time at $0 \mathrm{~min}$ ), the viscosity measured at $25{ }^{\circ} \mathrm{C}$ is higher than the one measured at $60{ }^{\circ} \mathrm{C}$. As the curing proceeded, the increase of viscosity was ascribed to the curing process of CEBs. As the curing process proceeded, the epoxy resin was crosslinked by the curing agent to larger molecules. Although the initial viscosity of CEBs measured at $60{ }^{\circ} \mathrm{C}$ was relatively low, a higher curing temperature induced a more intensive chemical reaction. As a result, CEB blends cured at $60{ }^{\circ} \mathrm{C}$ needed a shorter curing time to reach a specific viscosity. For example, it took $10 \mathrm{~min}$ for the viscosity of CEBs prepared by PM2 to reach $4800 \mathrm{mPa} \cdot \mathrm{s}$ when the curing temperature was fixed at $60{ }^{\circ} \mathrm{C}$, while the curing temperature was at $25^{\circ} \mathrm{C}$, the duration extended to $30 \mathrm{~min}$. An identical conclusion could be obtained in the cases of PM1 and PM3. Thus, the curing temperature is the decisive factor that influences the viscosity of CEBs.

Conversely, the viscosity evolution varied with the preparation methods, no matter the curing temperature. CEBs prepared by PM1 and PM3 complied with a similar tendency at $25^{\circ} \mathrm{C}$ and $60{ }^{\circ} \mathrm{C}$, respectively. As for CEBs prepared by PM2, the viscosity increased with curing time at a faster rate. The curing agent was added later in PM2. However, in PM3, the curing agent was mixed with bitumen before its incorporation into epoxy. Previous studies demonstrated that the presence of bitumen decreased the conversion rate of CEBs. The results shown herein further revealed that bitumen primarily reduces the probability of curing agent connecting to epoxy resin. However, premixing bitumen and epoxy resin into a stable blend followed by the incorporation of curing agents can accelerate the conversion of CEBs. The mechanism probability can also be used to explain the viscosity evolution prepared by PM1.

In practice, CEBs require sufficient viscosity for construction workability. For this reason, the workability intervals were accordingly summarized, as seen in Table 3. It can be concluded that increasing curing temperature significantly decreased the workability intervals. Based on the workability interval, the workability performance of different preparation methods was in line with PM3, PM1, PM2. In other words, the interval can be extended in practice by premixing bitumen and the curing agent. It is noticeable that the workability required for construction usually is longer than $30 \mathrm{~min}[24,41]$. It seems that

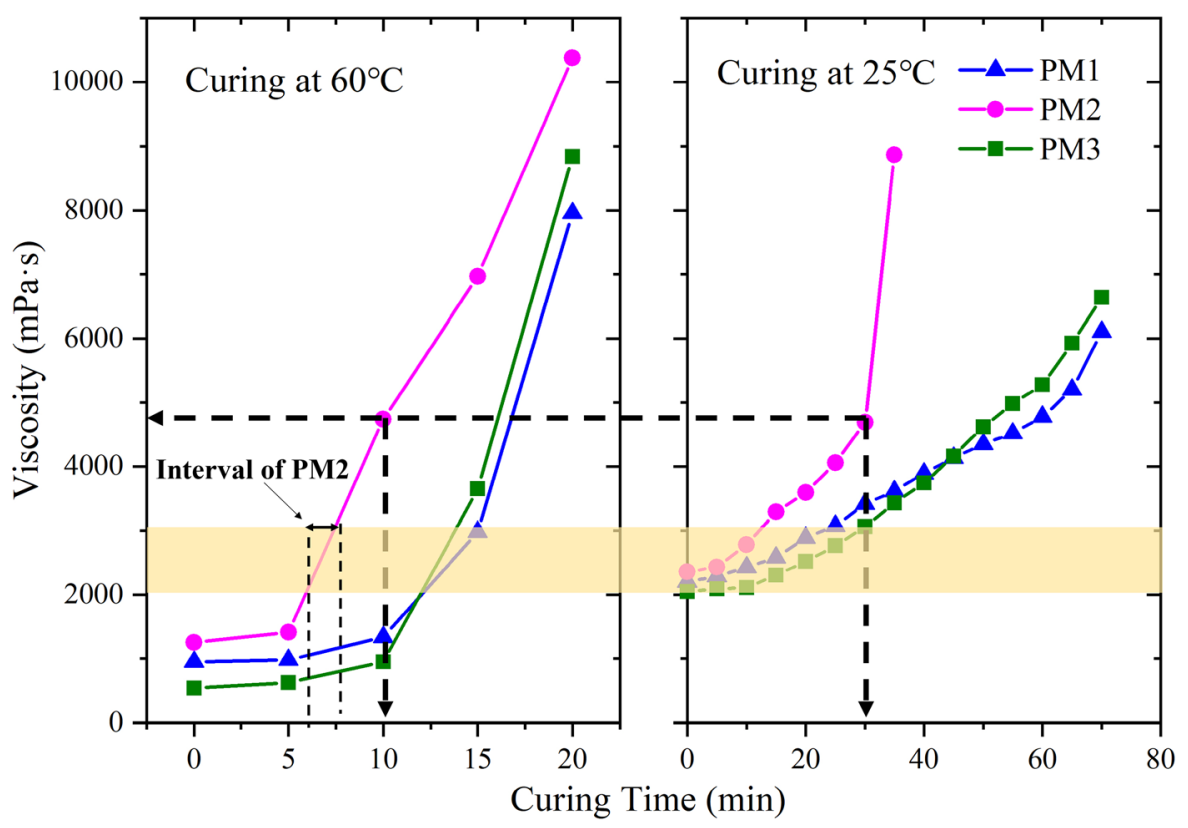

Fig. 3 Viscosity with time for CEBs at $25^{\circ} \mathrm{C}$ and $60{ }^{\circ} \mathrm{C}$ 
Table 3 Workability intervals for different preparation methods

\begin{tabular}{llll}
\hline & PM1 & PM2 & PM3 \\
\hline Interval @60 ${ }^{\circ} \mathrm{C}$ & $2.6 \mathrm{~min}$ & $1.6 \mathrm{~min}$ & $1.8 \mathrm{~min}$ \\
Interval @25 ${ }^{\circ} \mathrm{C}$ & $20 \mathrm{~min}$ & $12 \mathrm{~min}$ & $30 \mathrm{~min}$ \\
\hline
\end{tabular}

samples prepared in this study fail to satisfy the requirement. However, the short workability time can be extended by selecting another appropriate curing agent.

\subsection{Microscopic morphology of cured CEBs}

The morphology of cured CEBs using different methods was identified to characterize the phases and detailed particle size distribution, as shown in Fig. 4. The light phase represented the epoxy resin, and the black inclusions corresponded to bitumen. It can be seen that bitumen dispersed in the epoxy resin relatively uniformly for all preparation methods but with different particle size distributions. Also, the average area fraction of the bitumen-rich phase was calculated for each of the three methods. They are PM1 (40\%), PM2 (32.8\%), PM3 (38.6\%), respectively. It can be found that premixing bitumen with the curing agent (PM3) is beneficial for the dispersion of bitumen particles in the CEB blends, as indicated by comparing PM2 and PM3. In PM2, the bitumen was mixed with epoxy bitumen in advance, forming a stable blend. After adding the curing agent, the curing agent can easily interact with the epoxy resin, which leads to more intensive conversion than other methods. However, it is not good for the dispersion of bitumen using PM2.

The distribution of particle size was further analyzed quantitatively, as shown in Fig. 5. In general, the normal distribution function can be used to describe the particle distribution. Accordingly, the particle size for PM1 showed the largest medium value, around $60 \mu \mathrm{m}$. As for the PM2 and PM3, the medium value of particle size was around $30 \mu \mathrm{m}$ and $20 \mu \mathrm{m}$, respectively.

It is believed that a more uniform distribution with a small particle size is preferable for the performance of CEBs since the possible cluster could induce high interior stress concentration under external loading. In

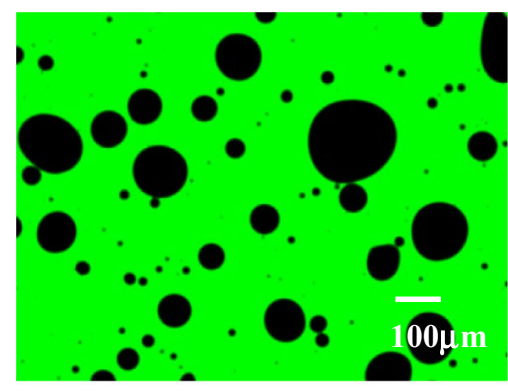

PM1-1

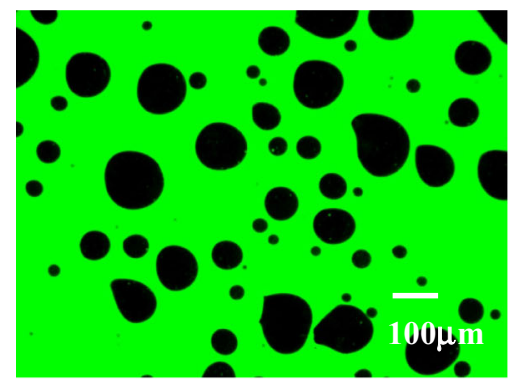

PM1-2

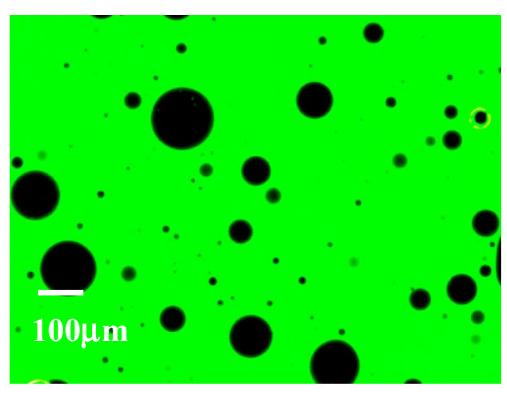

PM2-1

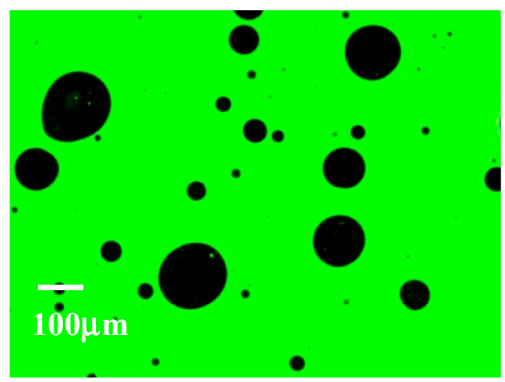

PM2-2

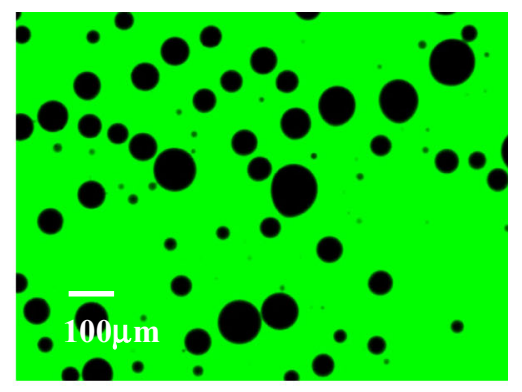

PM3-1

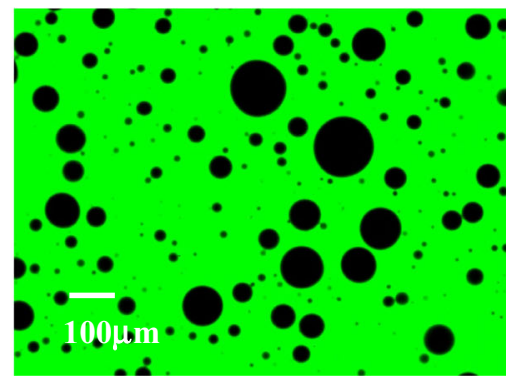

PM3-2

Fig. 4 Fluorescence images for different preparation methods 


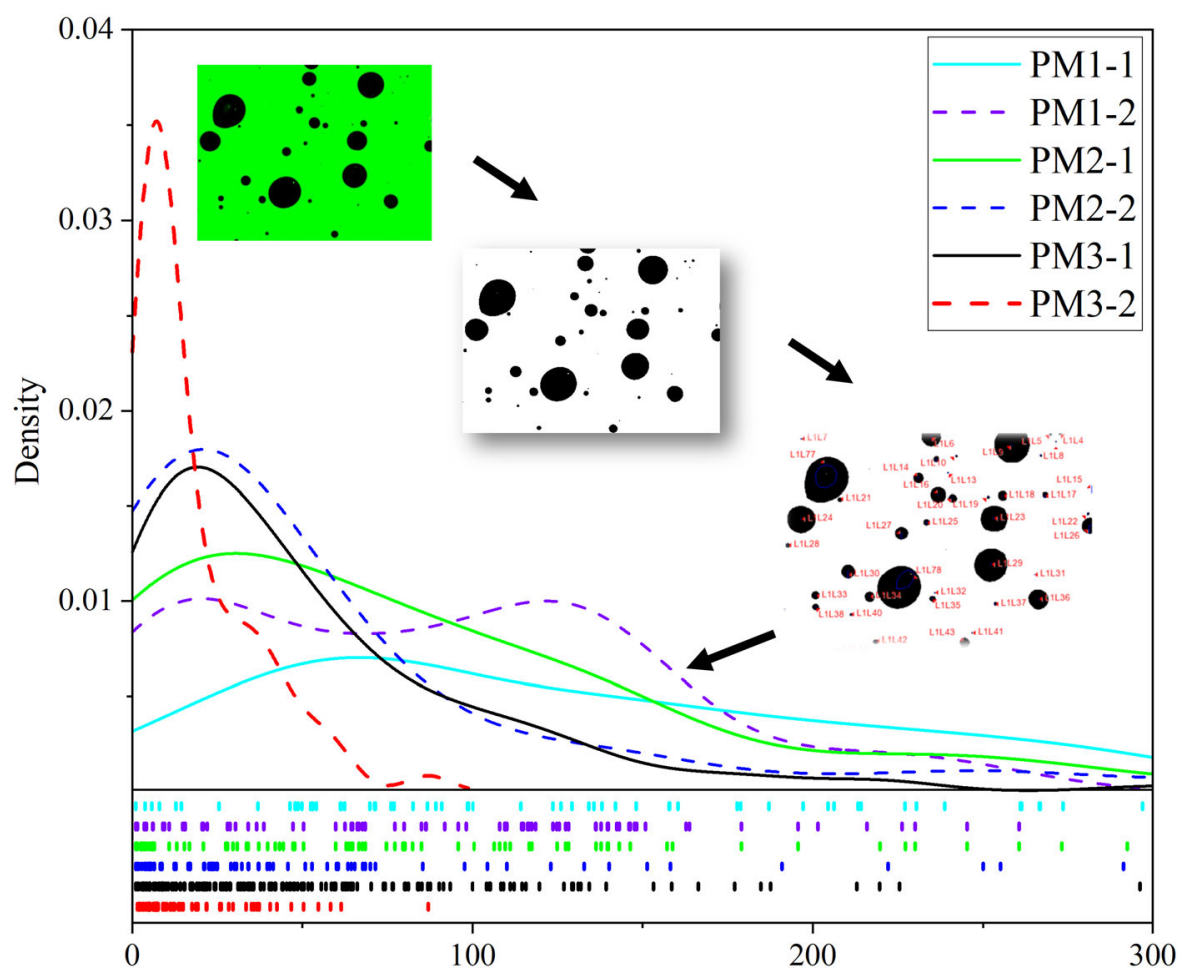

Fig. 5 Particle size distribution for three preparation methods (solid and dashed lines represent two parallel results)

this condition, CEBs using PM3 showed the best morphological property.

\subsection{Mechanical properties of cured CEBs}

The tensile test was performed to characterize the tensile strength and elongation at the breaking of cured CEBs (Fig. 6). The tensile strength of CEBs using PM1, PM2, and PM3, was 2.54 MPa, 1.42 MPa, and 5.27 MPa, respectively. The preparation method contributed significantly to the ultimate strength of the cured samples, as seen in that the tensile strength in the case of PM3 was approximately 3.7 and 2.1 times higher than that of PM2 and PM1, respectively. This conclusion complied with the morphology analysis, given that a relatively uniform and fine bitumen particle distribution leads to better mechanical performance.

The elongations at the breaking for PM1, PM2, and PM3 were $42 \%, 98 \%$, and $26 \%$, respectively. Due to the same epoxy resin content and bitumen, the only reason attributed to the variation is the dispersion of bitumen and epoxy resin. Comparing PM1 and PM3, the uniformity of CEBs using these two methods are comparable. A previous study indicated that the thermoplastic component (asphaltene and resin) contributed significantly to the elongation at breaking. In addition, the increased bitumen content could also induce an increase of elongation at breaking [41]. Hence, large bitumen particle size could result in better performance of elongation at breaking since bitumen played a dominant role in the elongation performance. As for the PM2, the elongation at breaking of CEBs showed the highest value. A plausible explanation could be the lowest strength of CEBs produced by PM2. The strength formation mechanical is fundamentally distinct from the other ones using PM1 and PM3.

\subsection{Dynamic Mechanical Analysis of cured CEBs}

This study performed the DMA to characterize the mechanical properties of CEBs as a function of the temperature (as shown in Fig. 7). CEBs with different preparation methods showed different dynamic mechanical properties. In PM2, the modulus fluctuated with temperature from $-30{ }^{\circ} \mathrm{C}$ to $30{ }^{\circ} \mathrm{C}$ on account of bitumen's unwanted dispersibility. This conclusion is 


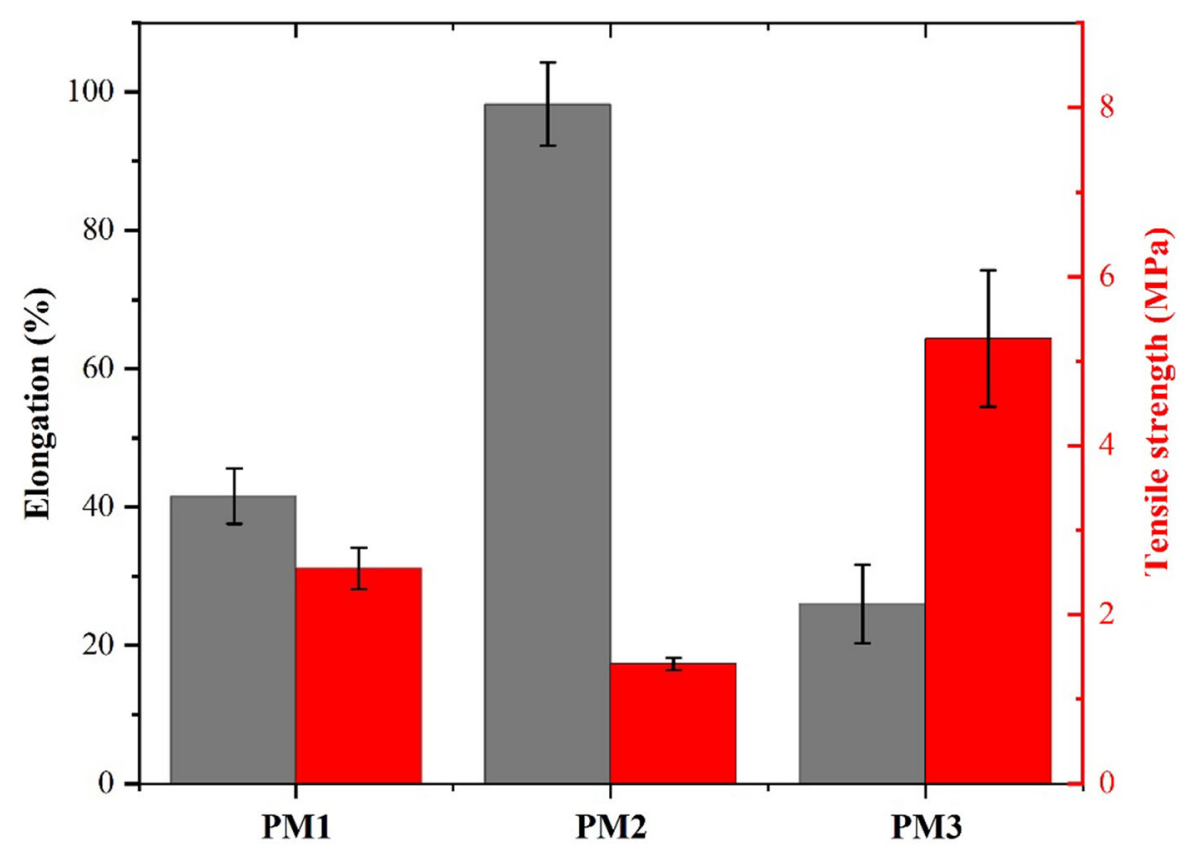

Fig. 6 Elongation at the breaking and tensile strength for three methods

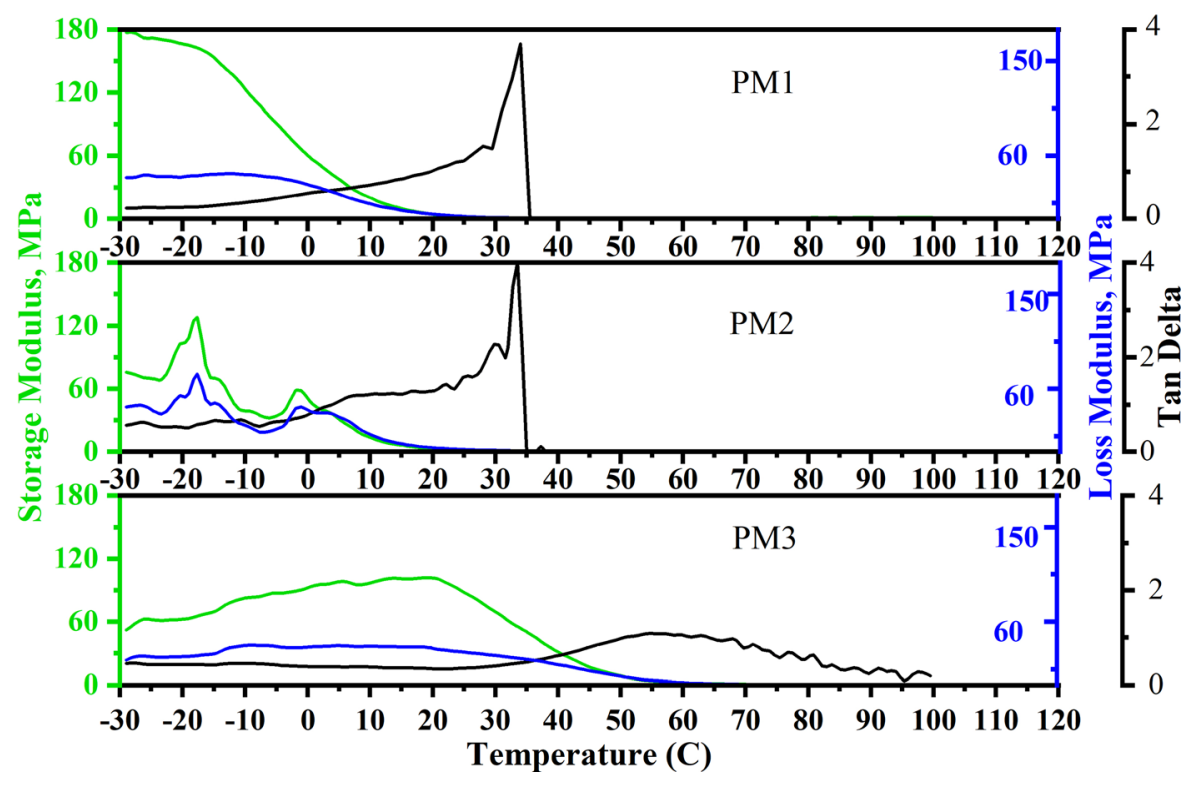

Fig. 7 DMA analysis of CEBs for three preparation methods

consistent with the results of the morphology and mechanical analysis. The modulus of CEB blends with PM1 decreased considerably as the temperature increased. In contrast, the modulus of CEB blends from PM3 changed smoothly with the temperature. CEB blends from PM3 possessed a lower temperature susceptibility than PM1, which indicated a relatively stable microstructure. The peak value of the phase angle corresponds to the glassy transition temperature of CEBs. As indicated, the glassy transition temperature of CEB from PM1 was around $33{ }^{\circ} \mathrm{C}$, which is 
significantly lower than that from PM3 (around $\left.55^{\circ} \mathrm{C}\right)$.

\subsection{Thermal stability of cured CEBs}

Figure 8 showed the TGA and derivative TGA (DTG) curves of bitumen and CEBs from all three preparation methods. The thermal degradation of bitumen underwent two distinct stages. The first stage took place around $413.6{ }^{\circ} \mathrm{C}$, relating to the elimination of some unsaturated functional groups. The second stage occurred around $468.6^{\circ} \mathrm{C}$ due to the degradation of the central carbon chain. The pyrolysis of CEBs presented three stages, although the first stage was not noticeable. The first stage appeared around $100{ }^{\circ} \mathrm{C}$, as seen $109.3{ }^{\circ} \mathrm{C}$ marked for the PM3. This degradation could be ascribed to the evaporation of diluent. The second stage for CEBs corresponded to the first stage of bitumen. The temperature at the second stage for
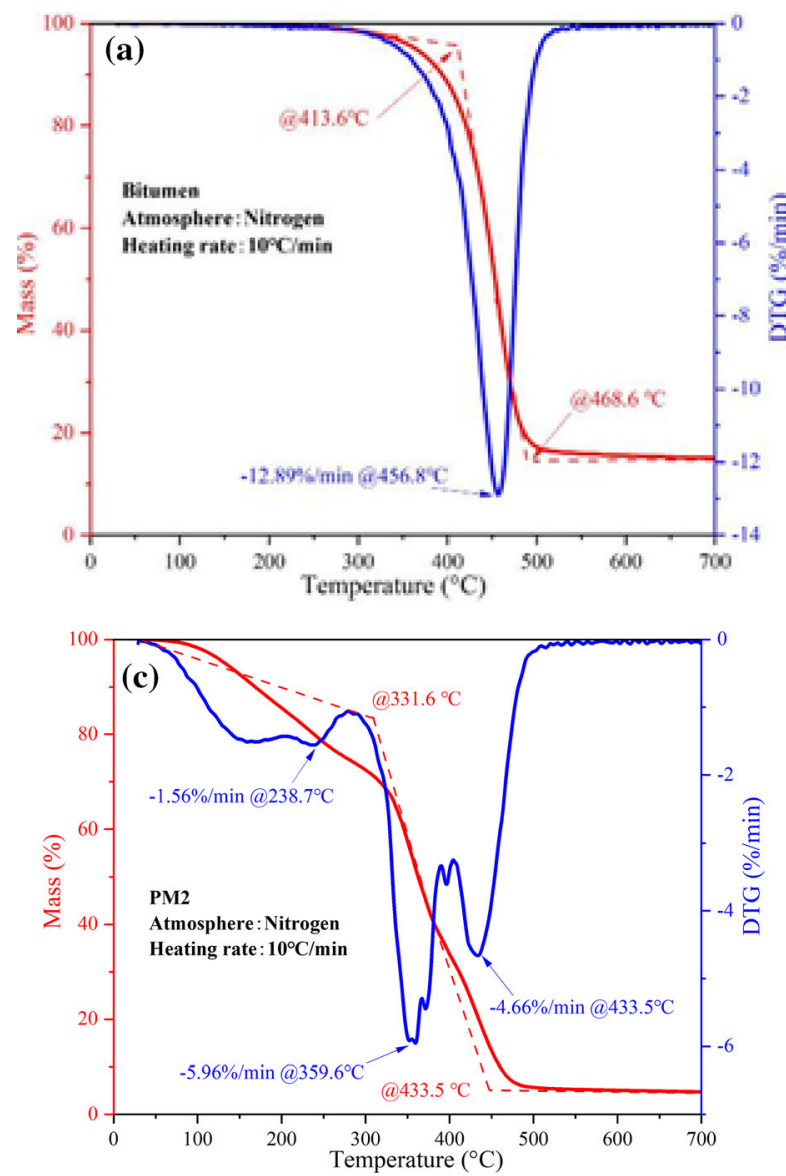

Fig. 8 TG and DTG results a Bitumen, b PM1, c PM2, d PM3
CEBs was lower than that for bitumen, as seen at the $308.2{ }^{\circ} \mathrm{C}$ for PM1, $331.6{ }^{\circ} \mathrm{C}$ for PM2, and $325.7{ }^{\circ} \mathrm{C}$ for PM3. This stage was because of the decomposition of the cross-linked network and the degradation of bitumen itself. In terms of the third stage, bitumen and CEBs were all alike. According to the DTG curves for the three mixing processes, it can be found that PM1 and PM3 were identical. In contrast, the DTG curve for PM2 showed significant fluctuation, which indicated the unwanted thermal stability for epoxy bitumen. This observation was consistent with the results of the morphological and mechanical properties.

\subsection{A summary of CEB performance with three preparation methods}

To better compare the variation of CEBs prepared with these three methods, Fig. 9 summarized several typical indicators to compare the pros and cons of the
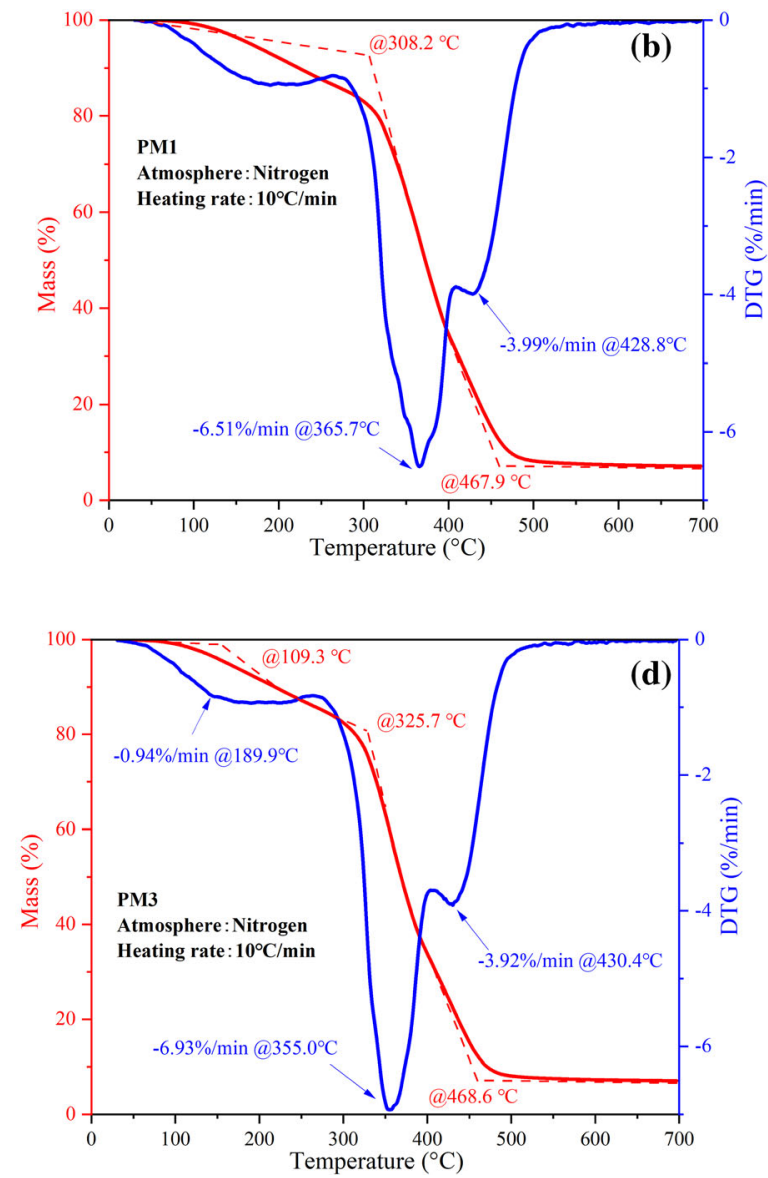


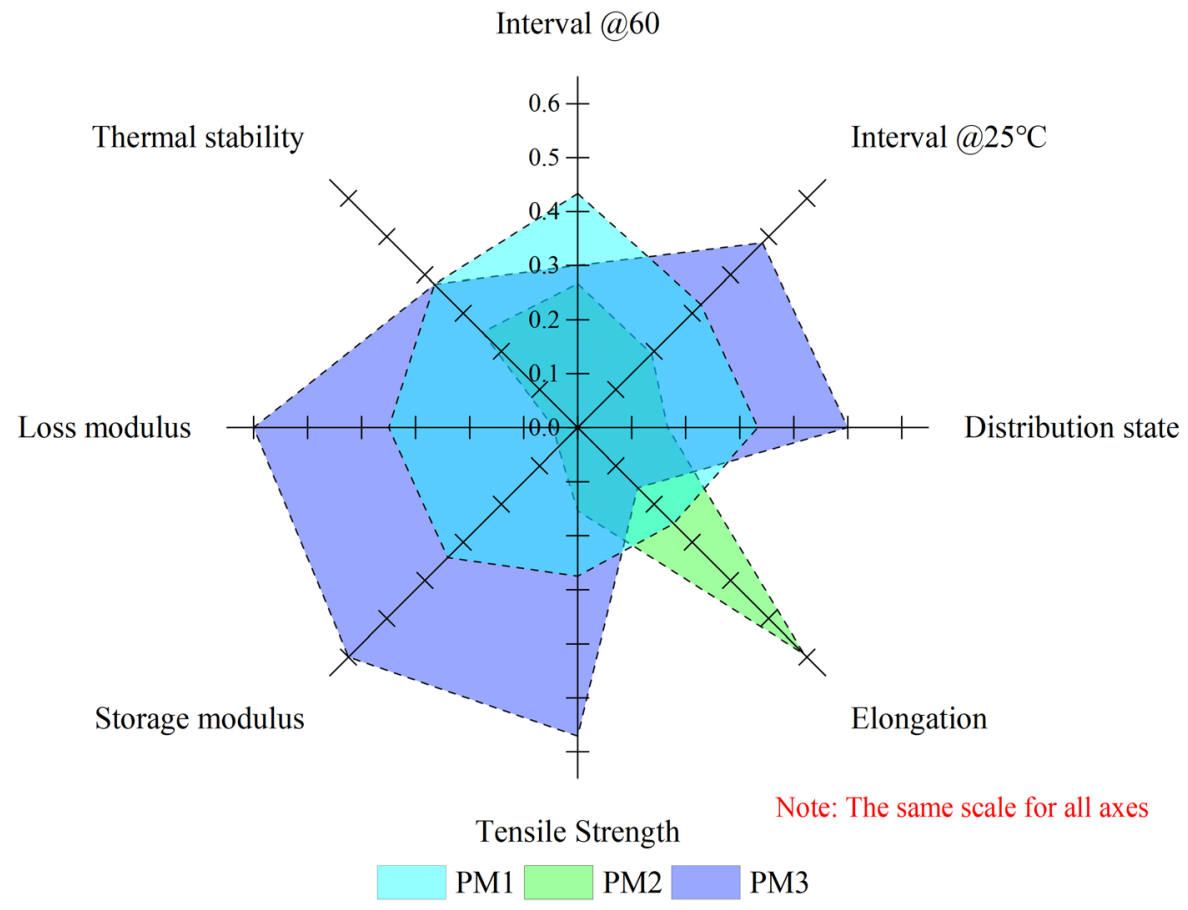

Fig. 9 Radar chart of typical properties for CEBs

three preparation methods. Part of the indicators were directly extracted from the measurements above. The others were subjectively judged (ranking 1-3) according to the analysis results. Moreover, for the benefit of comparison, all the indicators were then normalized to make the value between 0 and 1 .

All indicators with a larger value positively mean better performance in terms of the practical application. It is noticeable that CEBs prepared with PM3 showed the most expected performance, followed by the ones with PM1 and PM2. Based on the radar chart, it is not recommended to pre-mix the bitumen and epoxy when producing the cold-mixed epoxy bitumen. It is not surprising that PM1 and PM3 are both acceptable since the current market has related commercial products. The achievement of this study provides an insight into the influence of preparation methods on the performance of CEBs, which is an essential reference for other similar research and conditions.

\section{Conclusion}

To date, the cold-mixed epoxy bitumen (CEB) has attracted considerable interest in high-quality pavement construction due to its eco-friendly characteristics. However, a low mixing temperature and complicated composition considerably increase the difficulty of preparation, aiming to obtain high-quality construction. To this end, this study performed an investigation on three preparation methods of CEBs. The viscosity measurement monitored the conversion rate during the mixing process. The cured samples using each of the preparation methods were subjected to morphology analysis, mechanical tests, and thermal stability test. Some key findings are concluded as follows.

1) The curing temperature is the decisive factor that influences the conversion rate of $\mathrm{CEB}$ blends. In addition, the viscosity evolution was affected by the mixing sequence of components in CEBs. The contact probability between the curing agent and epoxy resin contributed to the variation of viscosity evolution.

2) Provided that the chemical compositions were the same, the morphological characteristics of 
cured CEB blends played a significant role in the mechanical performance of CEBs. In particular, the uniformity of particle distribution (bitumen-rich phase) and the medium value of particle size distribution mutually determined the tensile strength and elongation at the breaking of CEBs.

3) The superiority of investigated preparation methods was in line with PM3, PM1, and PM2. PM3 is classified into a two-component method, while PM1 refers to a three-component method. Due to the unwanted microstructures of CEBs, the PM2 is not recommended in this study.

Funding Open Access funding enabled and organized by Projekt DEAL. The authors would like to acknowledge the financial support provided by the German Research Foundation (OE 514/10-1) and the German Research Foundation (DFG, No. OE 514/1-2, FOR2089). The authors also gratefully acknowledge financial support from the China Scholarship Council (CSC No. 201706710009).

\section{Declarations}

Declarations The authors declare that they have no conflict of interest.

Open Access This article is licensed under a Creative Commons Attribution 4.0 International License, which permits use, sharing, adaptation, distribution and reproduction in any medium or format, as long as you give appropriate credit to the original author(s) and the source, provide a link to the Creative Commons licence, and indicate if changes were made. The images or other third party material in this article are included in the article's Creative Commons licence, unless indicated otherwise in a credit line to the material. If material is not included in the article's Creative Commons licence and your intended use is not permitted by statutory regulation or exceeds the permitted use, you will need to obtain permission directly from the copyright holder. To view a copy of this licence, visit http://creativecommons.org/licenses/by/4.0/.

\section{References}

1. Gao Y, Li L, Zhang Y (2020) Modeling crack propagation in bituminous binders under a rotational shear fatigue load using pseudo J-integral Paris' Law. Transp Res Rec J Transp Res Board. https://doi.org/10.1177/0361198119899151

2. Gao Y, Zhang Y, Gu F, Xu T, Wang H (2018) Impact of minerals and water on bitumen-mineral adhesion and debonding behaviours using molecular dynamics simulations. Constr Build Mater. https://doi.org/10.1016/j. conbuildmat.2018.03.136
3. Zhang Z, Oeser M (2020) Residual strength model and cumulative damage characterization of asphalt mixture subjected to repeated loading. Int J Fatigue 135:105534. https://doi.org/10.1016/j.ijfatigue.2020.105534

4. Wu J, Wang Y, Liu Q, Wang Y, Ago C, Oeser M (2020) Investigation on mechanical performance of porous asphalt mixtures treated with laboratory aging and moisture actions. Constr Build Mater 238:117694. https://doi.org/10.1016/j. conbuildmat.2019.117694

5. Wu J, Liu Q, Yang S, Oeser M, Ago C (2020) Study of migration and diffusion during the mixing process of asphalt mixtures with RAP. Road Mater Pavement Des. https://doi. org/10.1080/14680629.2019.1710237

6. Lu G, Liu P, Wang Y, Faßbender S, Wang D, Oeser M (2019) Development of a sustainable pervious pavement material using recycled ceramic aggregate and bio-based polyurethane binder. J Clean Prod 220:1052-1060. https:// doi.org/10.1016/j.jclepro.2019.02.184

7. Jin X, Guo N, You Z, Wang L, Wen Y, Tan Y (2020) Rheological properties and micro-characteristics of polyurethane composite modified asphalt. Constr Build Mater 234:2020. https://doi.org/10.1016/j.conbuildmat.2019. 117395

8. Li J, Yang S, Muhammad Y, Sahibzada M, Zhu Z, Liu T, Liao S (2020) Fabrication and application of polyurea formaldehyde-bioasphalt microcapsules as a secondary modifier for the preparation of high self-healing rate SBS modified asphalt. Constr Build Mater 246:118452. https:// doi.org/10.1016/j.conbuildmat.2020.118452

9. Ren S, Liang M, Fan W, Zhang Y, Qian C, He Y, Shi J (2018) Investigating the effects of SBR on the properties of gilsonite modified asphalt. Constr Build Mater 190:1103-1116. https://doi.org/10.1016/j.conbuildmat. 2018.09.190

10. Yan K, Chen J, You L, Tian S (2020) Characteristics of compound asphalt modified by waste tire rubber (WTR) and ethylene vinyl acetate (EVA): conventional, rheological, and microstructural properties. J Clean Prod 258:120732. https://doi.org/10.1016/j.jclepro.2020.120732

11. Mansourian A, Goahri AR, Khosrowshahi FK (2019) Performance evaluation of asphalt binder modified with EVA/ HDPE/nanoclay based on linear and non-linear viscoelastic behaviors. Constr Build Mater 208:554-563. https://doi. org/10.1016/j.conbuildmat.2019.03.065

12. Nakhaei M, Naderi K, Nasrekani AA, Timm DH (2018) Moisture resistance study on PE-wax and EBS-wax modified warm mix asphalt using chemical and mechanical procedures. Constr Build Mater 189:882-889. https://doi. org/10.1016/j.conbuildmat.2018.08.216

13. Wang Z, Zhang S (2018) Fatigue endurance limit of epoxy asphalt concrete pavement on the deck of long-span steel bridge. Int J Pavement Res Technol 11:408-415. https://doi. org/10.1016/j.ijprt.2017.12.004

14. Liu Y, Zhang J, Chen R, Cai J, Xi Z, Xie H (2017) Ethylene vinyl acetate copolymer modified epoxy asphalt binders: phase separation evolution and mechanical properties. Constr Build Mater 137:55-65. https://doi.org/10.1016/j. conbuildmat.2017.01.081

15. Song M, Liang R, Deng J, Kang Y (2017) Sealed accelerants facilitate epoxy asphalt concretes opening to traffic quickly. 
Constr Build Mater 147:1-8. https://doi.org/10.1016/j. conbuildmat.2017.04.148

16. Zhang YJ, Cao DW, Zhang HY, Wu XW (2013) The study of curing characteristics of epoxy asphalt. Adv Mater Res 785-786:295-299

17. Huang W, Guo W, Wei Y (2019) Thermal effect on rheological properties of epoxy asphalt mixture and stress prediction for bridge deck paving. J Mater Civ Eng. https://doi. org/10.1061/(ASCE)MT.1943-5533.0002861

18. Xiang Q, Xiao F (2020) Applications of epoxy materials in pavement engineering. Constr Build Mater 235:117529. https://doi.org/10.1016/j.conbuildmat.2019.117529

19. Jeyranpour F, Alahyarizadeh G, Arab B (2015) Comparative investigation of thermal and mechanical properties of cross-linked epoxy polymers with different curing agents by molecular dynamics simulation. J Mol Graph Model 62:157-164. https://doi.org/10.1016/j.jmgm.2015.09.012

20. Yu J, Cong P, Wu S (2009) Laboratory investigation of the properties of asphalt modified with epoxy resin. J Appl Polym Sci. https://doi.org/10.1002/app.30324

21. Zhou X, Wu S, Liu G, Pan P (2016) Molecular simulations and experimental evaluation on the curing of epoxy bitumen. Mater Struct Constr. https://doi.org/10.1617/s11527014-0491-4

22. Apostolidis P, Liu X, van de Ven M, Erkens S, Scarpas T (2019) Kinetic viscoelasticity of crosslinking epoxy asphalt. Transp Res Rec. https://doi.org/10.1177/ 0361198119835530

23. Yin H, Zhang Y, Sun Y, Xu W, Yu D, Xie H, Cheng R (2015) Performance of hot mix epoxy asphalt binder and its concrete. Mater Struct Constr 48:3825-3835. https://doi. org/10.1617/s11527-014-0442-0

24. Cong P, Luo W, Xu P, Zhang Y (2019) Chemical and physical properties of hot mixing epoxy asphalt binders. Constr Build Mater 198:1-9. https://doi.org/10.1016/j. conbuildmat.2018.11.275

25. Gong J, Liu Y, Jiang Y, Wang Q, Xi Z, Cai J, Xie H (2019) Performance of epoxy asphalt binder containing warm-mix asphalt additive. Int J Pavement Eng. https://doi.org/10. 1080/10298436.2019.1597272

26. Luo S, Liu Z, Yang X, Lu Q, Yin J (2019) Construction technology of warm and hot mix epoxy asphalt paving for long-span steel bridge. J Constr Eng Manag 145:04019074. https://doi.org/10.1061/(asce)co.1943-7862.0001716

27. Li R, Leng Z, Zhang Y, Ma X (2019) Preparation and characterization of waterborne epoxy modified bitumen emulsion as a potential high-performance cold binder. J Clean Prod 235:1265-1275. https://doi.org/10.1016/j. jclepro.2019.06.267

28. Li R, Leng Z, Partl MN, Raab C (2021) Characterization and modelling of creep and recovery behaviour of waterborne epoxy resin modified bitumen emulsion. Mater Struct Constr. https://doi.org/10.1617/s11527-020-01594-6
29. Zhang H, Gao P, Pan Y, Li K, Zhang Z, Geng F (2020) Development of cold-mix high-toughness resin and experimental research into its performance in a steel deck pavement. Constr Build Mater. https://doi.org/10.1016/j. conbuildmat.2019.117427

30. Chen R, Gong J, Jiang Y, Wang Q, Xi Z, Xie H (2018) Halogen-free flame retarded cold-mix epoxy asphalt binders: rheological, thermal and mechanical characterization. Constr Build Mater 186:863-870. https://doi.org/10.1016/j. conbuildmat.2018.08.018

31. Si J, Li Y, Wang J, Niyigena AR, Yu X, Jiang R (2020) Improving the compatibility of cold-mixed epoxy asphalt based on the epoxidized soybean oil. Constr Build Mater. https://doi.org/10.1016/j.conbuildmat.2020.118235

32. Luo S, Lu Q, Qian Z, Wang H, Huang Y (2017) Laboratory investigation and numerical simulation of the rutting performance of double-layer surfacing structure for steel bridge decks. Constr Build Mater 144:178-187. https://doi.org/10. 1016/j.conbuildmat.2017.03.172

33. Drews A (2008) Standard Test Method for Penetration of Bituminous Materials, Man. Hydrocarb. Anal. 6th Ed. 47-47-3. https://doi.org/10.1520/mnl10829m

34. A. D113, Standard test method for ductility of bituminous materials, Annu. B. Stand. (2007)

35. ASTM, ASTM D4402-06 Standard test method for viscosity determination of asphalt at elevated temperatures using a rotational viscometer. In: Annu. B. ASTM Stand. 2006, pp 1-4. https://doi.org/10.1520/D4402-06.2

36. Drews A (2008) Standard Test Method for Softening Point of Bitumen (Ring-and-Ball Apparatus), Man. Hydrocarb. Anal. 6th Ed, pp 50-50-4. https://doi.org/10.1520/ mnl10830m

37. A. International, ASTM D70-09, Standard Test Method for Density of Semi-Solid Bituminous Materials (Pycnometer Method), (2009)

38. D. ASTM (2015) Standard test method for viscosity determination of asphalt at elevated temperatures using a rotational viscometer. Am Soc Test Mater

39. Soenen H, Lu X, Redelius P (2008) The morphology of bitumen-SBS blends by UV microscopy: an evaluation of preparation methods. Road Mater Pavement Des 9:97-110. https://doi.org/10.1080/14680629.2008.9690109

40. Standard A (2010) D638-10, 2010. Stand. Test Methods Tensile Prop. Plast. ASTM Int, West Conshohocken, PA

41. Si J, Li Y, Yu X (2019) Curing behavior and mechanical properties of an eco-friendly cold-mixed epoxy asphalt. Mater Struct Constr 52:1-11. https://doi.org/10.1617/ s11527-019-1382-5

Publisher's Note Springer Nature remains neutral with regard to jurisdictional claims in published maps and institutional affiliations. 